\title{
AS RELAÇÕES ÉTNICO-RACIAIS NO COTIDIANO DE PSICÓLOGOS DO SISTEMA ÚNICO DE ASSISTÊNCIA SOCIAL (SUAS) DA CIDADE DE SÃO PAULO
}

\section{THE ETHNIC-RACIAL RELATIONS ON DAILY ROUTINE OF PSYCHOLOGISTS THAT WORK IN THE UNIFIED SYSTEM OF SOCIAL ASSISTANCE IN SÃO PAULO}

\author{
Rodolfo Luis Almeida Maia \\ Alessandro de Oliveira dos Santos \\ E-mail para correspondência: alos@usp.br
}

Marcelo Jardim dos Santos

\section{RESUMO}

Este texto analisa como psicólogos que trabalham no Sistema Único de Assistência Social (SUAS) da cidade de São Paulo são interpelados pelo tema das relações étnico-raciais em sua prática profissional. Para isto, foi realizada uma análise de conteúdo de entrevistas com sete psicólogos que trabalham em serviços de diferentes níveis de complexidade na rede SUAS. A análise evidenciou que a prática do psicólogo no campo da assistência social carece de repertórios (conteúdos e habilidades) para lidar com as relações étnico-raciais na rede SUAS. Os entrevistados mostraram pouco conhecimento sobre aspectos históricos e sociais das re- 
lações étnico-raciais no Brasil, bem como sobre os efeitos psicossociais do racismo, isto é, o preconceito e a discriminação étnico-racial. Isso ocorre por conta do atual modelo de assistência social, majoritariamente material e baseado em fornecer soluções para demandas concretas e, portanto, com dificuldade em absorver e lidar com o tema. E também devido a ausência de uma reflexão mais densa sobre as relações étnico-raciais pelos cursos de psicologia, cuja formação ainda tem contribuído pouco para uma atuação profissional na rede SUAS dedicada à compreensão de marcadores sociais importantes da produção das vulnerabilidades sociais e desigualdades no Brasil, como a raça-etnia.

Palavras-chave: Assistência Social; Psicologia Social; relações étnico-raciais; vulnerabilidade social, desigualdade social.

\section{ABSTRACT}

This paper analyzes and discusses how psychologists working in the Unified Social Assistance System in São Paulo are questioned by the ethnic-racial relations in their professional practice. A content analysis was made regarding interviews with seven psychologists working in different levels of services complexity in the Unified Social Assistance System. The analysis showed that the psychologist practice in the field of social welfare lacks repertoires (content and skills) to deal with the issue of ethnic and racial relations in network services of Unified Social Assistance System. Respondents showed little knowledge about the historical and social aspects of ethnic-racial relations in Brazil and about the psychosocial effects of racism, that is, prejudice and ethnic and racial discrimination. This occurs because of the current model of social assistance based on materialism and providing concrete solutions to specific demands, therefore, with difficulties to absorb and deal with the issue. And also due to not appropriating a more profound reflection on the ethnic-racial relations by psychology courses, whose training has not contributed a lot to a professional practice in the Unified Social Assistance System dedicated to the understanding of importance social markers of the production of social vulnerabilities and inequalities, such as, race-ethnicity.

Keywords: Social Assistance; Social Psychology; ethnic-racial relations; social vulnerabilities; social inequalities.

\section{INTRODUÇÃO}

As políticas públicas de assistência social no Brasil referem-se ao conjunto de medidas adotadas pelo poder público que visam a proteção social de pessoas, famílias e comunidades no enfrentamento de situações de vulnerabilidade, assegurando a garantia de direitos e de condições de vida dignas. Durante a Ditadura Militar (1964-1985) a assistência social esteve diretamente vinculada à previdência 
social. Desse modo, apenas aqueles que contribuíam financeiramente com o Sistema de Previdência do país podiam se beneficiar do atendimento em seguridade social.

Com a Constituição de 1988 o acesso à assistência social enquanto direito foi garantido para toda população brasileira por meio do Artigo 203 (Constituição da República Federativa do Brasil, 1988) que no seu parágrafo único determina:

A assistência social realiza-se de forma integrada às políticas setoriais, visando ao enfrentamento da pobreza, à garantia dos mínimos sociais, ao provimento de condições para atender contingências sociais e à universalização dos direitos sociais.

Contudo, apesar de garantido o direito universal à seguridade social pela Constituição, fez-se necessário a definição de políticas operacionais capazes de colocar em prática o acesso a tal direito. Isto ocorreu em 1993 com a publicação da Lei Orgânica da Assistência Social (LOAS) que estabeleceu as diretrizes para a criação de um Sistema Único de Assistência Social (SUAS) no país. Mas, somente em 2004 com a sanção da Política Nacional de Assistência Social (PNAS) o SUAS conseguiu ser efetivamente implantado. Com isto, definiu-se uma rede de atendimento com diferentes equipamentos públicos.

A rede SUAS prevê três níveis de atendimento em termos de complexidade, organizados em dois serviços municipalizados: os Centros de Referência de Assistência Social (CRAS), responsáveis pela proteção social básica, de baixa complexidade; e os Centros de Referência Especializada de Assistência Social (CREAS), responsáveis pela proteção social de média e alta complexidade (Ministério do Desenvolvimento Social e Combate à fome [MDS], 2011). Segundo Couto (2003) o trabalho realizado nesses serviços tem como princípio o fortalecimento da autoestima e dos vínculos familiares, comunitários e sociais dos usuários.

Na cidade de São Paulo, a rede SUAS se configurou a partir de serviços públicos que já existiam voltados, por exemplo, para o atendimento de crianças e adultos que viviam na rua. Atualmente, na cidade, os serviços, em sua maioria, são fruto de parcerias público-privadas entre entidades privadas e organizações não governamentais (ONG). Não há uma homogeneidade nestas entidades, que são classificadas e certificadas de acordo com as necessidades do município, tendo como parâmetro regulamentador a Resolução 27, publicada em 2011, pelo Conselho Nacional de Assistência Social - CNAS (SMADS, 2013). A Figura 1 a seguir mostra a estrutura da rede SUAS em São Paulo:

De acordo com a Secretaria Municipal de Assistência e Desenvolvimento Social de São Paulo, a cidade tem 1.333 equipamentos de assistência social, destinados à proteção social básica, proteção social especial, programas de transferência de renda e sócio-assistenciais. Dentre estes, 1.263 estão relacionadas a convênios com entidades privadas e ONGs e 70 são geridos diretamente pela Prefeitura (SMADS, 2013). 


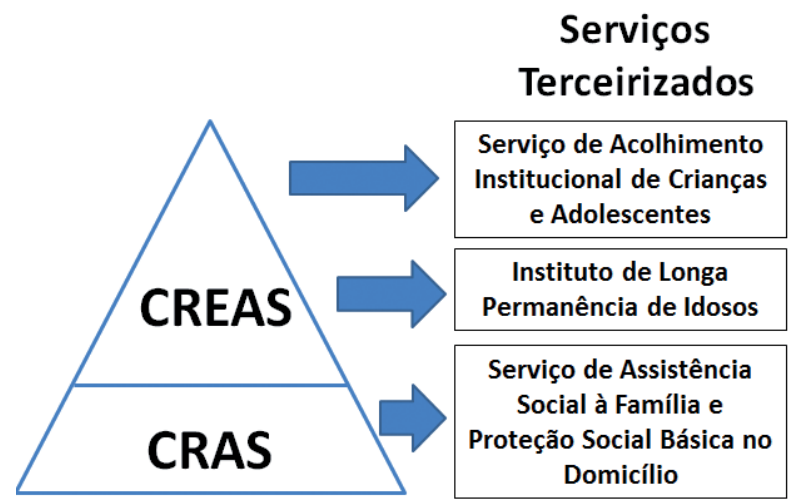

Figura 1 Estrutura da rede SUAS da cidade de São Paulo.

Fonte: Elaborada pelos autores.

Segundo o último Censo SUAS de 2014, os equipamentos de São Paulo contam com cerca de 14.000 psicólogos, revelando um campo importante de trabalho para esses profissionais no âmbito das políticas públicas, visto que se trata da segunda maior categoria em atividade na rede SUAS, ficando atrás apenas dos assistentes sociais (MDS, 2015).

Entretanto, o trabalho dos psicólogos no campo da assistência social é recente no Brasil e coloca desafios. Em primeiro lugar, pelo fato dos psicólogos terem sido convocados a trabalhar no campo antes mesmo dele ser objeto de reflexão, estudo e estágio no âmbito dos cursos de graduação em psicologia. Em segundo lugar, pelo fato da assistência social, enquanto política de seguridade social, impor a estes profissionais o debate sobre o compromisso social da psicologia no enfrentamento dos problemas nacionais, como as desigualdades e as várias formas de opressão e violência (Couto, 2003).

Para Yamamoto (2003) a prática profissional dos psicólogos foi socialmente legitimada com base em um credencialismo, ou seja, na institucionalização da formação e regulação da atividade profissional, sustentando um discurso de propriedade de conhecimento capaz de definir quem é competente ou não para tratar de determinados assuntos e populações. Nas palavras do autor, a profissão: "teria por pressuposto a apropriação deste conhecimento por parte de um grupo que estabelece critérios de credenciamento" (p. 39), por conseguinte, a aplicação de tais conhecimentos ou não no atendimento aos diversos segmentos da população brasileira terá, necessariamente, a exclusão de certos grupos como uma de suas contrapartidas.

É neste ponto que a formação em psicologia ganha relevância no sentido de contribuir para perpetuar discursos sobre quem pode ser incluído ou excluído da 
práxis do profissional psicólogo. Segundo Senra e Guzzo (2012), os psicólogos que atuam na rede SUAS reclamam da falta de subsídios durante a graduação para trabalhar no campo da assistência social. Para as autoras, as práticas tradicionais, predominantemente clínicas e individuais, ainda prevalecem como norte de trabalho dos psicólogos nesses serviços, sem considerar, muitas vezes, determinantes sociais importantes, como as desigualdades na configuração do sofrimento psíquico.

Nas décadas de 1960 e 1970, as clínicas particulares concentravam a maior parte dos psicólogos, sendo poucos os brasileiros que tinham acesso aos seus serviços. No final da década de 1980 , devido a abertura política, este quadro mudou. Com a redemocratização do país, os psicólogos foram chamados a trabalhar na operacionalização de políticas públicas de saúde, no âmbito do Sistema Único de Saúde (SUS) e na assistência social, no âmbito da rede SUAS. Isto mudou o perfil da clientela atendida e esses profissionais começaram a ser confrontados, em suas práticas, pelas desigualdades persistentes no Brasil e como estas se expressam na configuração das relações étnico-raciais entre brancos e negros no país.

De fato, a longa história de colonização e escravidão no Brasil precisa ser tomada em consideração pelos psicólogos. No país, por conta desse processo histórico e da ausência de políticas visando sua reparação, a renda, a escolaridade, a habitação e as condições de saúde são sempre menores e/ou piores entre os negros quando comparados aos brancos. Diversas ciências como a História, Demografia, Saúde Coletiva, tem mostrado a relevância da raça-etnia como um marcador social importante para compreensão da vulnerabilidade social de indivíduos e coletividades e das desigualdades no Brasil.

A raça-etnia é um constructo sociológico, que só faz sentido em um contexto histórico, visto que não é possível definir geneticamente diferentes raças-etnias humanas. Ao lado de gênero e classe social, ela é uma categoria que constitui, diferencia, hierarquiza e localiza as pessoas na sociedade (Schucman, 2014). No Brasil, a raça-etnia é distintiva de uma diferença em termos sociais cujo racismo é a ideologia resultante. Trata-se de uma ideologia, segundo a qual existiria raças-etnias puras, superiores umas as outras, com características transmitidas hereditariamente que determinam e são reconhecidas através da cor da pele, traços de inteligência e caráter e manifestações culturais (Guimarães 2003). Ao longo dos séculos, o racismo tem sido utilizado para justificar diferentes formas de opressão e violência e a manutenção das desigualdades (Santos, 2012).

No Brasil, a população negra ocupa as camadas mais baixas da sociedade, encontrando-se em situação de maior vulnerabilidade social ou sem condições mínimas para manter uma vida digna, sendo, por conseguinte, aquela que mais acessa os serviços públicos. O racismo direcionado a essa população produz, 
como efeitos psicossociais, o preconceito e a discriminação, favorecendo a violação de seus direitos e a ampliação de seus contextos de vulnerabilidade social. No campo da saúde, por exemplo, mulheres negras têm menor chance de fazer consultas ginecológicas, de pré-natal e de receber as informações necessárias sobre o parto. Também apresentam maior probabilidade de ter o primeiro filho antes dos 16 anos de idade e maior índice de mortalidade materna em relação às mães brancas (Lopes, 2005). O que indica a dificuldade dos profissionais que trabalham nesses serviços em garantir a igualdade étnico-racial nos atendimentos em saúde prestados.

A presença dos psicólogos nos serviços públicos tem crescido nos últimos anos, exigindo a reflexão desses profissionais sobre temas centrais para compreensão da vulnerabilidade social e das desigualdades no Brasil, como as relações étnico-raciais. Este texto apresenta parte dos resultados de um estudo maior ${ }^{1}$ sobre como as relações étnico-raciais aparecem no cotidiano de psicólogos que atuam em diferentes campos (saúde, educação, recursos humanos, assistência social). O texto analisa e discute especificamente como psicólogos que trabalham na rede SUAS da cidade de São Paulo são interpelados por este tema em sua prática profissional.

\section{MÉTODO}

Foi realizado um estudo qualitativo descritivo de caráter exploratório por meio de entrevistas com 7 psicólogos, sendo 5 mulheres e 2 homens, com idade entre 24 e 55 anos. Dentre estes, 2 trabalhavam em um CRAS da periferia da Zona Leste de São Paulo, 3 trabalhavam em um CREAS da região central da cidade e 2 trabalhavam em um Instituição de Longa Permanência para Idosos (ILPI) na Zona Norte de São Paulo. Os entrevistados foram convidados a participar voluntariamente do estudo por meio de carta-convite, enviada através de e-mail e redes sociais. A coleta dos dados ocorreu ao longo do ano de 2015, mediante assinatura de Termo de Consentimento Livre e Esclarecido pelos entrevistados. A Tabela 1 contém informações sobre o perfil dos psicólogos que participaram do estudo:

1 O estudo “Atuação de psicólogos no tema das relações étnico-raciais” está sendo realizado desde 2013 na cidade de São Paulo, sob a coordenação de Alessandro de Oliveira dos Santos e conta com apoio da Fundação de Amparo à Pesquisa do Estado de São Paulo (FAPESP) (Processo 2013/11199-2). 
Tabela 1 Informações sobre o perfil dos psicólogos entrevistados.

\begin{tabular}{|c|c|c|c|c|}
\hline $\begin{array}{c}\text { Nome } \\
\text { (fictício) }\end{array}$ & Idade & $\begin{array}{c}\text { Raça-etnia } \\
\text { (autodeclarada) }\end{array}$ & $\begin{array}{c}\text { Serviço onde } \\
\text { trabalha }\end{array}$ & $\begin{array}{c}\text { Região onde } \\
\text { trabalha }\end{array}$ \\
\hline Ana & 25 & Parda & CREAS & Centro \\
\hline Beatriz & 24 & Negra & CREAS & Centro \\
\hline Carolina & 55 & Branca & CREAS & Centro \\
\hline Denise & 36 & Branca & ILPI & Norte \\
\hline Eduardo & 25 & Negro & ILPI & Norte \\
\hline Fernando & 53 & Branco & CRAS & Leste \\
\hline Gabriela & 46 & Branca & CRAS & Leste \\
\hline
\end{tabular}

Fonte: Elaborada pelos autores.

As entrevistas duraram em média 45 minutos e foram realizadas no ambiente de trabalho dos entrevistados com base em um roteiro de questões. As perguntas do roteiro produziram informações sobre a concepção dos entrevistados acerca das relações étnico-raciais no Brasil e se o tema havia sido abordado durante a graduação. Também permitiram coletar cenas de preconceito e discriminação étnico-racial, ouvidas, testemunhadas ou vividas por eles no cotidiano do trabalho.

O conceito de cena utilizado por Paiva (1999), para investigar a sexualidade entre jovens, foi adaptado neste estudo para coletar informações sobre episódios de preconceito e discriminação. A consigna para a descrição dessas cenas se traduziu na seguinte instrução aos entrevistados: "Na sua prática profissional você já ouviu falar ou testemunhou algum caso ou situação em que tenha vindo à tona as diferenças raciais, étnicas, a cor da pele das pessoas ou problemáticas relacionadas ao racismo? Se sim, você poderia relatar?”. A descrição de uma cena singular por uma ou mais pessoas, pode ser coletada através de uma entrevista individual ou em grupo e permite identificar a interação dinâmica das dimensões pessoais, culturais, institucionais, em cada situação concreta da qual as pessoas participam. Desse modo, ajuda a compreender o que facilita ou dificulta respostas individuais e coletivas.

Todas as entrevistas foram gravadas e o material transcrito. Em seguida, foi feita uma análise buscando os principais conteúdos que emergiram. Posteriormente, houve o agrupamento desses conteúdos em duas categorias: invisibilidade das relações étnico-raciais; e cenas de preconceito e discriminação étnico-racial no cotidiano do trabalho.

A construção das categorias foi realizada com base nas similaridades temáticas presentes nos relatos, de modo a permitir agrupamentos e discussões mais homogêneas sobre os conteúdos (Carlomagno \& Rocha, 2016). Ao final, foram selecionados excertos de relatos dos entrevistados para exemplificar os conteúdos recorrentes em cada categoria. 


\section{RESULTADOS}

\section{Invisibilidade das relações étnico-raciais}

Um dos objetivos da entrevista foi levantar informações sobre como o tema das relações étnico-raciais era abordado nos cursos de psicologia. Para isto, perguntou-se se durante a graduação os entrevistados haviam visto ou trabalhado assuntos como raça-etnia ou racismo em alguma disciplina. Dos sete psicólogos, três afirmaram que o tema foi tratado de forma superficial na graduação, como mostram os relatos a seguir:

Não! Nem passou perto! [do tema relações étnico-raciais] A gente teve uma discussão provocada pelo meu grupo no meu primeiro ano de faculdade (Fernando, 53 anos, branco).

Chegou a ser trabalhado de maneira, perto do que deveria ser considerado, de maneira muito sucinta. E era uma questão que quando você começava a debater, especialmente eu. . . A galera me classificava como neurótico. Quando você é ligado nestas questões (Eduardo, 25 anos, negro).

Como disciplina explícita, não. Mas houve sim durante a formação e foi muito pouco ... durante disciplinas relacionadas à psicologia social e cultural, em que foram abordadas as questões do preconceito de um modo geral a gays, negros, judeus, portadores de síndrome de Down (Ana, 25 anos, parda).

Bento (2002) afirma que as relações étnico-raciais no Brasil são, em geral, um tema associado apenas as pessoas de cor de pele negra, sendo que a posição das pessoas de cor de pele branca pouco emerge nessas discussões. Segundo Eduardo, por exemplo, quando o tema foi abordado por ele na sala de aula gerou incômodo nos colegas, em sua maioria de cor de pele branca, que o chamaram de "neurótico". Nesse ponto, a predominância da cor de pele dos estudantes e psicólogos brasileiros vêm à tona, como comenta Fernando:

Eu vou falar para você que eu me formei em 1984 e eu conheci três [psicólogos negros]! Negros? Três (Fernando, 53 anos, branco).

A predominância da cor de pele branca dos estudantes e psicólogos anunciada por Fernando contribui para uma dificuldade dos mesmos em se perceberem como também tendo um pertencimento étnico-racial. Schucman (2014) chama atenção para neutralidade que as pessoas de cor de pele branca adquirem nas relações sociais no país e as características positivas de moralidade, intelectualidade e estética 
que lhes são automaticamente atribuídas, enquanto representantes de um padrão considerado universal de ser humano. Neste sentido, a entrevistada Ana pontua:

É um processo inconsciente. Uma pessoa branca é mais próxima de um padrão do que se considera como "correto" é por isso que as pessoas preferem sentar do lado de um branco ... . você se sente seguro mais próximo do igual. Estas ideias, de certa forma, refletem algumas noções de etnia, como quando imaginamos um ladrão, ele sempre é negro (Ana, 25 anos, parda).

A pessoa de cor de pele branca é considerada o padrão ideal e reflete a identidade de grupo constituída pelos próprios brancos. Elias e Scotson (2000) pontuam que as relações de poder são um reflexo da capacidade dos grupos em se apropriarem de identidades coletivas, ou seja, quanto mais no centro das relações de poder se encontra um grupo, maior sua capacidade de manipular a autoimagem e a imagem dos outros grupos. Nesse sentido, um bom exemplo da neutralidade da cor de pele branca nas relações sociais pode ser verificado pelo fato dos entrevistados autodeclarados brancos não se perceberem com pertencimento étnico-racial, atribuindo tal pertencimento aqueles que eles consideravam não brancos, em especial aos negros e nordestinos, como mostra os relatos abaixo:

No caso de racismo aqui no Brasil . . . eu estou pensando em algumas coisas que a gente vê né? Como, por exemplo, ... todas as pessoas que as empresas, estas de construção civil, vão até o Nordeste, chamam para vir fazer o trabalho aqui e aí termina o trabalho e larga elas aqui (Gabriela, 46 anos, branca).

Eu não sei se existem grupos raciais hoje no país. Acho que talvez em alguns estados seja um pouco mais significativo. A Bahia, por exemplo, é um estado que talvez seja muito mais forte esta questão da raça. Não sei se aqui no estado de São Paulo isto aconteça (Carolina, 55 anos, branca).

A gente sabe que existe [racismo], a gente convive, mas a gente não para refletir, né? ... eu nunca parei para pensar assim na atuação [profissional]. Agora que estou pensando nisto porque o [psicólogo negro] entrou para nossa equipe. A gente percebeu algumas coisas e ele trouxe estas reflexões . . . a gente sabe que existe ... mas não se aprofunda (Denise, 36 anos, branca).

Uma das características mais marcantes das desigualdades no Brasil diz respeito ao domínio de determinados postos de trabalho pelas pessoas de cor de pele branca. Segundo Eduardo, a psicologia, enquanto profissão, também reflete este processo: 
O psicólogo, muitas vezes na nossa sociedade não cabe na figura de um negro... O fato de eu ser psicólogo tem este ponto: "Mas você não tem cara de psicólogo". E psicólogo tem cara? Para as pessoas tem! Nas fantasias das pessoas o psicólogo é branco, tem olho claro, usa óculos, né? É um pouco também do ideário que eu tinha de psicólogo, daquilo que eu tinha na ideia de ser psicólogo e de quem se constitui como tal. Tanto nas suas práticas como na cor de pele (Eduardo, 25 anos, negro).

Como destaca Bento (2002), desde o fim da escravidão a vinda dos imigrantes europeus cumpriu o objetivo de monopolizar determinados postos de trabalho, excluindo assim os negros:

A monopolização dos postos de trabalho pelos imigrantes europeus, na sociedade de classes que emergia, interpretado como fruto de um melhor preparo desses imigrantes, foi posteriormente contestado por vários estudiosos. $\mathrm{Na}$ verdade, o que se deu foi a mais cristalina discriminação com o objetivo explícito de excluir o negro, uma vez que os imigrantes que aqui vieram tinham o mesmo nível de preparo. Assim, omissão e inércia não são bons conceitos para caracterizar a atitude da elite branca da época (p. 47).

Nesse sentido, a compreensão das relações étnico-raciais exige a investigação das identidades coletivas de brancos e de negros e de como elas dialogam entre si, visto que ambas se configuram e se mantêm pelas posições que as pessoas ocupam dentro de relações de poder. Bourdieu (1983) questiona o papel dos pensadores e acadêmicos na sustentação das relações de poder entre esses dois grupos. Para o autor:

Estamos sempre prontos a estigmatizar o estigmatizador, a denunciar o racismo elementar, "vulgar". Mas é fácil demais. Temos que fazer o papel dos credores endividados e nos perguntarmos qual é a contribuição que os intelectuais dão ao racismo da inteligência. Seria bom estudar o papel dos médicos na medicalização, isto é, na naturalização das diferenças sociais, dos estigmas sociais, e o papel dos psicólogos, dos psiquiatras e dos psicanalistas na produção dos eufemismos que permitem designar os filhos de sub-proletários ou de emigrados de tal forma que os casos sociais se tornam casos psicológicos, as deficiências sociais, deficiências mentais (p. 205).

A pouca formação sobre as relações étnico-raciais, aliada a neutralidade do próprio pertencimento étnico-racial, gera uma ausência de repertório sobre relações étnico-raciais entre os psicólogos que pode ser constatada pela incapacidade 
dos entrevistados em tratar e diferenciar conceitualmente termos como racismo, discriminação e preconceito étnico-racial, como exemplificam os relatos a seguir:

Eu acho que [os três conceitos] são muito próximos. . . A gente discrimina porque a gente não conhece, não aceita. Acho que discriminação é um comportamento. . . Muito ruim ... Muito ofensivo (Denise, 36 anos, branca).

$\mathrm{Eu}$ acho que pode até haver um significado mais teórico entre os três [conceitos]. Com certeza deve ter, mas acho que estão muito juntos (Carolina, 55 anos, branca).

Tá misturando tudo! Acho que eu vou acabar chegando na mesma conclusão em todos! Acho que esta tudo ali. Nunca pensei muito nisso (Beatriz, 24 anos, negra).

Ademais, constatou-se a partir das entrevistas que as discussões sobre relações étnico-raciais, racismo, preconceito e discriminação étnico-racial, quando ocorreram no âmbito da formação em psicologia ou da prática profissional se deram por conta de pessoas envolvidas com esses temas, e não por ser um aspecto relevante das desigualdades no Brasil e/ou uma diretriz dos serviços que compõem a rede SUAS.

As relações étnico-raciais entre brancos e negros compõem um aspecto importante das relações sociais brasileiras e têm sido objeto de estudo da psicologia desde seu início no país (Leite, 1966; Souza, 1982; Santos, Schucman \& Martins, 2012). Os relatos dos entrevistados reforçam a necessidade de que o tema seja abordado com profundidade nos cursos de graduação e que os psicólogos se apropriem da tradição de estudos da psicologia no Brasil sobre o tema.

\section{Cenas de preconceito e discriminação étnico-racial no cotidiano do trabalho}

Para coletar dados sobre como as relações étnico-raciais aparecem no trabalho dos psicólogos, os entrevistados foram perguntados se durante a prática profissional já ouviram falar ou testemunharam algum episódio que tenha emergido o pertencimento étnico-racial, seja dos profissionais ou dos usuários da rede SUAS. Nesse sentido, chamou a atenção os relatos de dois entrevistados que trabalham no mesmo serviço com a mesma população. Eles, responderam de forma distinta, se já tinham ouvido falar ou testemunhado cenas de preconceito e/ou discriminação étnico-racial no serviço:

Não. Nesse daqui pelo menos não (Gabriela, 46 anos, branca).

Todos os dias tem pelo menos uma situação (Fernando, 53 anos, branco). 
Dentre os entrevistados, quatro negaram ter ouvido falar ou testemunhado cenas de preconceito e/ou discriminação étnico-racial, seja pessoalmente ou em relação à população atendida na rede SUAS. Porém, dois entrevistados comentaram que essa demanda pode não estar sendo percebida, como mostram os relatos a seguir:

Eu não cheguei a atender nenhum caso que envolvia diretamente questões relacionadas ao racismo. Talvez por conta da dificuldade de identificação por parte dos profissionais e da dificuldade de trazer isto para o serviço por parte dos usuários. $\mathrm{Na}$ verdade, eu não sei bem se eu posso falar se não houve ou se nós simplesmente não nos atentamos aos fatos (Ana, 25 anos, parda).

Não diretamente. Mas se eu for parar para pensar, a gente atende muitas pessoas em situação de rua, crianças e adolescentes . . . em sua grande maioria, as pessoas que a gente atende são negras. Existem pessoas brancas, pardas ... mas em sua maioria são negras (Beatriz, 24 anos, negra).

Por mais que na legislação brasileira a proteção social se caracterize pelo acolhimento psicossocial universal, na prática, o atendimento psicológico oferecido na rede SUAS ainda é majoritariamente material e baseado em fornecer soluções para demandas específicas e concretas da pessoa e/ou seu núcleo familiar. Desse modo, as questões que saem deste escopo não encontram espaço dentro da rede SUAS. Em outras palavras, se o usuário não apresentar uma demanda concreta relacionada ao preconceito e/ou discriminação étnico-racial, não há como lidar com estes fenômenos. Por outro lado, as manifestações de preconceito e/ou discriminação étnico-racial no Brasil se dão de forma implícita, o que dificulta seu processo de identificação e ao mesmo tempo contribui para negar o marcador social da raça-etnia como um determinante importante de produção da vulnerabilidade social e das desigualdades (Munanga, 2002).

Desse modo, a maioria dos entrevistados afirmou não ter ouvido falar ou testemunhado cenas de preconceito e/ou discriminação étnico-racial no cotidiano da prática profissional e possuem uma concepção de que é prejudicial considerar a raça-etnia dos usuários no atendimento nos serviços, como exemplifica o relato a seguir:

Nem presenciei e tampouco tive qualquer dificuldade em relação a isto. . . $\mathrm{Na}$ assistência social nós nos isentamos de qualquer tipo de preconceito ou julgamento, então não há do meu ponto de vista, diferença (Carolina, 55 anos, branca). 
Este relato é significativo porque revela uma postura defensiva no que se refere à consideração das relações étnico-raciais, indicando uma concepção equivocada de que dar relevância a esse tema no atendimento pode ser associado a uma prática preconceituosa. Ademais, reflete uma concepção universalista de humano, tributária de modelos teóricos clássicos da psicologia. O ser humano "abstrato e universal” de que se ocupam muitas teorias clássicas ensinadas na graduação em psicologia ainda reforça o pressuposto de que o ser humano é único, com características de certa forma fixas, independentemente das condições e contexto em que se encontre. O que diminui a capacidade de categorias utilizadas na atualidade para investigar e compreender as desigualdades, a opressão e a violência, como, por exemplo, a raça-etnia, de atualizar essas teorias.

Além disso, como já comentado, do ponto de vista simbólico, a figura do psicólogo também reproduziria esse universalismo das teorias clássicas, por conseguinte, esse profissional seria sempre de cor de pele branca, não cabendo nesta posição uma pessoa de cor de pele negra. Neste sentido, o modo como os psicólogos negros que trabalham na rede SUAS são confrontados em seu trabalho ajuda a desvelar como o pertencimento étnico-racial atravessa a prática profissional. A análise de conteúdo das entrevistas com esses psicólogos mostra que uma pessoa de cor de pele negra na posição de psicólogo tem sua credibilidade constantemente questionada, revelando uma desvantagem no mercado de trabalho. Isso se evidencia tanto na cena de preconceito étnico-racial testemunhada por Denise, como na cena de discriminação étnico-racial vivenciada por Eduardo:

Tem uma idosa, ela tem um problema psiquiátrico e ela é bastante preconceituosa. Então ela briga muito com o [psicólogo negro] e fala: "Esse negro maldito! Eu não quero saber dele!”. . . Diretamente, este é o caso que a gente tem mais conhecimento (Denise, 36 anos, branca).

Eu cheguei no portão da instituição e não fui questionado de quem eu me tratava, quem eu era ou para o que eu fui falar. Eu fui orientado a buscar o Centro de Amparo ao Trabalhador que eles iriam me encaminhar para o centro de acolhida. E neste momento eu me identifiquei que eu não era mendigo, eu era técnico psicólogo (Eduardo, 25 anos, negro).

A diferença entre preconceito e discriminação étnico-racial é importante. O preconceito étnico-racial refere-se às atitudes e juízos pré-concebidos a respeito de pessoas ou grupos de determinada raça-etnia e que não são facilmente modificáveis por apresentação de evidência contrária. Já a discriminação étnico-racial refere-se a toda distinção, exclusão ou restrição baseada na raça-etnia e capaz de pôr em risco as liberdades fundamentais e os direitos em quaisquer 
esferas (Santos, 2012). A cena abaixo, relatada por Fernando, exemplifica a manifestação dos dois fenômenos quando ocorrem juntos:

Vou destacar uma [cena] de pessoa com deficiência... Mesmo diagnóstico de uma síndrome: um [usuário] branco, loiro de olhos claros e um negro. $\mathrm{E}$ o tratamento dispensado aos dois completamente diferente. Porque a pessoa que fazia a avaliação defendia categoricamente que o negro tinha menor potencial, e na origem da história, era sabido, dizia essa pessoa, através da antropologia, que os negros tinham um cérebro menor e um menor potencial de desenvolvimento. Então ele estava cedendo a vaga naquele serviço para o menino branco porque ela tinha certeza que o branco teria mais potencial de desenvolvimento e o negro já tinha atingido todo seu potencial (Fernando, 53 anos, branco).

Nesta cena, não se trata apenas de preconceito étnico-racial, visto que a profissional negou o benefício de um serviço da rede SUAS a um usuário de cor de pele negra, discriminando, com base em seu preconceito, uma criança negra ao impedir seu acesso a uma oportunidade dentro do serviço. E, desse modo, perpetuando a manutenção das desigualdades entre brancos e negros no país.

\section{CONSIDERAÇÕES FINAIS}

De acordo com Faro e Pereira (2011), as pessoas pertencentes aos grupos minoritários politicamente possuem uma maior probabilidade de crescer em ambientes socialmente desfavorecidos e, consequentemente, apresentarem dificuldades em seu desenvolvimento físico e psíquico. Nesse contexto, a cor da pele no Brasil aparece intrinsecamente associada a discrepâncias no acesso aos recursos necessários para o pleno desenvolvimento humano.

A análise de conteúdo das entrevistas mostrou que a prática do psicólogo no campo da assistência social carece de repertórios (conteúdos e habilidades) para lidar com o tema das relações étnico-raciais na rede SUAS. Os entrevistados mostraram pouco conhecimento sobre os aspectos históricos e sociais das relações étnico-raciais no Brasil, bem como sobre os efeitos psicossociais do racismo, isto é, o preconceito e a discriminação étnico-racial. Isso ocorre por conta do atual modelo de assistência social, majoritariamente material e baseado em fornecer soluções para demandas concretas, havendo, portanto, dificuldade em absorver e lidar com temas que escapam desse escopo. E, também, devido à ausência de uma reflexão mais densa sobre as relações étnico-raciais pelos cursos de psicologia, cuja formação ainda tem contribuído pouco para uma atuação profissional na rede SUAS dedicada à compreensão de marcadores sociais importantes da produção de 
vulnerabilidades sociais e desigualdades no Brasil, como, a raça-etnia. O que, por conseguinte, torna mais difícil reconhecer sua relevância e traz implicações para a prática profissional, como exemplificado pelas cenas de preconceito e discriminação étnico-racial ocorridas no cotidiano de trabalho dos entrevistados.

Além disso, a rede SUAS apresenta limitações, principalmente no contexto paulistano, por carregar vestígios de uma lógica assistencialista. Essa característica dificulta a realização de intervenções mais específicas de enfrentamento do racismo e seus efeitos psicossociais (preconceito e discriminação). Tais intervenções deveriam ser políticas institucionalizadas na rede SUAS, mas continuam a depender exclusivamente da abertura individual dos profissionais para discutir as relações étnico-raciais.

Segundo Martin-Baró (1996), antes de buscar definir os objetos de estudo da psicologia é preciso estar atento ao contexto no qual esta ciência está inserida, pois: "as definições genéricas procedentes de outros lugares trazem uma compreensão de nós mesmos e dos outros, muitas vezes, míope diante das realidades que a maioria dos nossos povos enfrenta" (p. 8). Esta questão é fundamental porque diz respeito ao que fazer da psicologia, no sentido do efeito objetivo que essa atividade produz na sociedade.

Concordamos com Dimenstein (2000) quando afirma que no Brasil a formação em psicologia se caracteriza por não possibilitar ao estudante o conhecimento de aspectos sócio-históricos que determinam sua formação. A psicologia cresceu no Brasil como suporte científico das ideologias dominantes e exerceu muito pouco o papel questionador e transformador das instituições e das relações sociais. Segundo a autora, a psicologia: "penetrou em toda a sociedade sem estar necessariamente comprometida com a produção de conhecimentos na perspectiva de transformação das práticas e ideologias dominantes em nossa sociedade” (p. 103).

Esse modelo do que fazer em psicologia acaba consolidando a imagem do psicólogo voltado para a clínica particular e o atendimento individual. Esta é a imagem mais conhecida e valorizada desse profissional e que acaba conduzindo a formação nos cursos de graduação. O que irá acarretar em problemas na prática profissional dentro dos serviços públicos, pois as pessoas atendidas, geralmente de baixa renda, possuem demandas que diferem substancialmente das que são atendidas na clínica particular em psicologia, para as quais a formação é direcionada.

Destarte, a inserção desse profissional na rede SUAS tem sido fundamental para abalar as estruturas consolidadas a formação em psicologia, indicando que os cursos de graduação precisam investir mais na sistematização de práticas e fazeres que se comprometam com o enfrentamento dos problemas nacionais e a transformação da realidade social brasileira (Senra \& Guzzo, 2012).

A postura desses profissionais é fundamental para a sustentação e reprodução ou não de formas diferenciadas de tratamento no âmbito dos serviços públi- 
cos e pode ser identificada em comportamentos que resultam em preconceito e discriminação por ignorância, falta de atenção ou mesmo negligência. As relações étnico-raciais são um tema importante para os psicólogos, que devem lidar com seu pertencimento étnico-racial, visto que ainda temos uma maioria de psicólogos de cor de pele branca, e com o fato da raça-etnia ser um marcador social importante nas formas de acesso e tratamento no âmbito dos serviços públicos disponíveis a população brasileira.

\section{REFERÊNCIAS}

Bento, M. A. S. (2002). Branqueamento e branquitude no Brasil. In: Carone, I. \& Bento, M. A. S. (Orgs.). Psicologia social do racismo: estudos sobre branquitude e branqueamento no Brasil. p. 25-57. Petrópolis, RJ: Vozes.

Bourdieu, P. (1983). Questões de sociologia. Rio de Janeiro, RJ: Marco Zero.

Carlomagno, M. \& Rocha, L. (2016). Como criar e classificar categorias para fazer análise de conteúdo: uma questão metodológica. Revista Eletrônica de Ciência Política, 7(1),173 -188.

Constituição da República Federativa do Brasil de 1988. (2016). Recuperado de: http:// www.planalto.gov.br/ccivil_03/Constituicao/Constituicao.htm

Couto, B. R. (2003). O Sistema Único de Assistência Social - SUAS: na consolidação da Assistência Social enquanto política pública. In: Couto, Silva \& Raichelis (Org.), O Sistema Único de Assistência Social no Brasil - uma realidade em movimento. p. 4155. Petrópolis, RJ: Vozes.

Dimenstein, M. (2000). A cultura profissional do psicólogo e o ideário individualista: implicações para a prática no campo da assistência pública à saúde. Estudos de Psicologia, 5(1), 95-121.

Elias, N. \& Scotson, J. L. (2000). Os estabelecidos e os outsiders: sociologia das relações de poder a partir de uma pequena comunidade. Rio de Janeiro, RJ: Zahar.

Faro, A. \& Pereira, M. E. (2011). Raça, racismo e saúde: a desigualdade social da distribuição do estresse. Estudos de psicologia, 16(3), 271-278.

Guimarães, A. S. (2003). Como trabalhar com "raça" em sociologia. Educação e Pesquisa, 29(1), 93-107.

Leite, D. M. ([1966], 2008). Diferenças psicológicas entre raças. In: Leite, D. M. (Org.). Psicologia diferencial e estudos em educação. p. 95-102. São Paulo, SP: Editora da UNESP.

Lopes, F. (2005). Para além da barreira dos números: desigualdades raciais e saúde. Cadernos de Saúde Pública, Rio de Janeiro, 21(5), 1595-1601.

Martin-Baró, I. (1996). O papel do Psicólogo. Estudos de psicologia, 2(1), 7-27.

MDS - Ministério do Desenvolvimento Social e Combate à Fome (2011). Assistência Social. Recuperado de: http: http://www.mds.gov.br/suas/conheca/conheca04.asp. 
MDS - Ministério do Desenvolvimento Social e Combate à Fome (2015). Censo SUAS 2014. Recuperado de: http://aplicacoes.mds.gov.br/sagi/snas/vigilancia/index2.php.

Munanga, K. (2002). Prefácio. In: Carone, I. \& Bento, M. A. S. (Orgs.). Psicologia social do racismo: estudos sobre branquitude e branqueamento no Brasil. p. 9-11. Petrópolis, RJ: Vozes.

Paiva, V. S. F. (1999). Cenas sexuais, roteiros de gênero e sujeito sexual. In: Barbosa, R. M. \& Parker, R. (Org.), Sexualidades pelo avesso: direitos, identidades e poder. p. 247-269. São Paulo, SP: Editora 34.

Santos, A. O. (2012). Superar o racismo e promover a saúde da população negra: desafios para o trabalho de prevenção ao HIV/Aids no Brasil. In: Paiva, Ayres \& Buchalla (Org.), Vulnerabilidade e Direitos Humanos. Prevenção e Promoção da Saúde. Da Doença à Cidadania. p. 145-163. Curitiba, PR: Juruá Editora.

Santos, A. O., Schucman, L. V. \& Martins, H. V. (2012). Breve histórico do pensamento psicológico brasileiro sobre relações étnico-raciais. Psicologia: Ciência e Profissão, 32, 166-175.

Schucman, L. V. (2014). Sim, nós somos racistas: estudo psicossocial da branquitude paulistana. Psicologia \& Sociedade, 26(1), 83-94.

Senra, C. M. G. \& Guzzo, R. S. L. (2012). Assistência social e psicologia: sobre as tensões e conflitos do psicólogo no cotidiano do serviço público. Psicologia \& Sociedade, 24(2), 293-299.

SMADS: Secretaria Municipal de Assistência e Desenvolvimento Social (2013). Prefeitura do Município de São Paulo. Recuperado de: http://www.prefeitura.sp. gov.br/cidade/secretarias/assistencia_social.

Souza, N. S. (1982). Tornar-se negro. Rio de Janeiro, RJ: Graal.

Yamamoto, O. H. (2003). Questão social e políticas públicas: revendo o compromisso da Psicologia. In: A. B. Bock (Org.), Psicologia e o Compromisso Social (p. 37-54). São Paulo, SP: Cortez. 
